\title{
DOSSIÊ TEMÁTICO: LITERATURA E ENSINO
}

\section{APRESENTAÇÃO}

Pesquisas voltadas para a leitura literária na escola não são mais tão reduzidas quanto há mais de uma década, quando foi criado o Mestrado em Linguagem e Ensino - POSLE - na Universidade Federal de Campina Grande. Indicadores do crescimento das reflexões e das pesquisas voltadas para o ensino de literatura, lançando mão de diversos gêneros literários, são o crescente número de dossiês voltados para o tema, bem como os vários livros que trazem resultado de pesquisas e projetos em andamento nesta área do conhecimento. A título de exemplo, lembramos o dossiê da revista Graphos - (UFPB, vol. 10, $\mathrm{n}^{\mathrm{o}}$ 1, 2008); da revista da ABRALIC $\left(\mathrm{N}^{\mathrm{o}} 22,2013\right)$ e da revista Educar em Revista (n ${ }^{\circ} 52$, 2014, Editora da UFPR), dentre outras ${ }^{1}$. O que se observa é que as reflexões sobre literatura e ensino, antes predominantes no sudeste e sul do país, agora se alastram por vários estados, o que propicia uma maior divulgação e acesso às das novas pesquisas e experiências voltadas para o ensino.

Todas estas reflexões tomaram um impulso maior com o advento dos PCN no final dos anos noventa e em 2006 com as OCEM - documento da maior importância para se pensar um ensino de literatura renovador, preocupado com a formação de leitores.

Há, por outro lado, uma diversidade de perspectivas teóricas que enriquecem sobremaneira os caminhos de abordagem do texto literário. O que parece comum entre elas é o fato de privilegiar o leitor como sujeito da leitura. Muitas retomam as teorias do letramento para propor novas abordagens do texto literário; outras retomam a sociologia da leitura, algumas se apoiam em teorias da recepção, ou ainda que se articulam às pesquisas de natureza etnográfica, realizadas no âmbito da educação. Todas estas perspectivas, a seu modo, enriquecem os caminhos que estão sendo abertos para o ensino da literatura na escola básica.

É neste contexto que a revista Leia Escola, cuja especificidade sempre foi divulgar estudos, pesquisas, ensaios e entrevistas que discutam o ensino de Línguas e Literatura, traz um pequeno Dossiê voltado para literatura e seu ensino. Os artigos que o compõe relatam e refletem sobre resultados de experimentos pontuais, realizados no contexto escolar, sobre a poesia infantil de um importante poeta contemporâneo e sobre a contribuição da poetisa Henriqueta Lisboa na organização de antologias poéticas para infância e juventude. Embora não proposital, a predominância do gênero lírico ficou em destaque no Dossiê, o que não se constitui um problema, uma vez que as experiências com a poesia são ainda inferiores aos demais gêneros, sobretudo à narrativa.

A entrevista com a professora dra. Vânia Maria Resende, uma das pioneiras na criação da disciplina literatura Infanto-juvenil e na divulgação de perspectivas novas para o ensino de literatura, além de questões históricas, como o primeiro encontro de professores de Literatura Infanto-juvenil na década de 1970, traz reflexões agudas sobre a importância e o lugar que a literatura deveria ocupar no processo educativo, bem como a memória sobre experiências significativas, com Concursos literários voltados para crianças e jovens, a importância do PROLER na promoção da leitura em diferentes espaços do país e reflexões sobre projetos mais recentes, como o PNBE. O leitor terá grande proveito se buscar a riqueza da produção de Vania Resende em

\footnotetext{
${ }^{1}$ Dentre as obras mais recentes destacamos: 1. MILREU, Iris, RODRIGUES, M. Candeia (org) Ensino de Língua e Literatura: políticas, práticas e projetos. Campina Grande: EDUFCG/Bagagem, 2012; ALVES, J. H. Pinheiro (org) Memórias da Borborema: discutindo a literatura e seu ensino. Campina Grande: ABRALIC, 2014; CAMARGO, F. Pereira, VIEIRA, M. M. Cardoso, FONSECA, Vilma N. da Silva (org) Olhares críticos sobre Literatura e ensino. São Paulo: Fonte Editorial, 2014; SIBALDO, M. Amorim (org) O texto literário na educação infantil: teoria e prática. Recife: PIPA, 2014; SÁ JÚNIOR, L. Araújo de, OLIVEIRA, Andrey P. (org) Literatura e ensino: reflexões e propostas. Natal: EDUFRN, 2014; NOBREGA, Maria M. S. Silva, PINHEIRO, Hélder (org). Literatura e ensino: aspectos metodológicos e críticos. Campina Grande: Editora da UFCG, 2014.
} 
seus livros - de crítica e de metodologia do ensino de literatura - que são rapidamente referidos. Destacamos um momento da entrevista em que a professora afirma: "Para que se chegue a isso [uma consolidação de acesso democrático e de qualidade aos bens culturais como o livro e a leitura literária], o ato de ler tem que se definir e ser vivido como experiência contínua, não circunstancial; em tal condição é que a leitura flui na sociedade, na cultura e na educação como necessidade natural, cotidiana, espontânea e livre, não se confundindo com eventos, nem ficando na dependência deles, ou restrita ao incentivo do momento."

$\mathrm{O}$ artigo de Ana Lúcia M. de S. Neves, As antologias organizadas pela escritora Henriqueta Lisboa nas décadas de 1960 e 1970, põe em evidência o importante trabalho de organização de antologias, voltadas para crianças e jovens, realizado pela poetisa. Num país continental como o nosso, em que as publicações de livros de poemas sempre teve um alcance mínimo, as antologias podem suprir algumas lacunas na formação do leitor bem como ser um importante indicador de descobertas de novos escritores. O trabalho de Henriqueta, como destaca Ana Lúcia Neves, traz uma concepção de educação estética que dialoga com o pensamento de Schiller, como se pode observar na retomada dos prefácios das várias antologias. Tanto as antologias quanto as concepções sobre poesia e educação estética permanecem atuais e necessárias. Conforme Ana Lúcia, “A educadora conhecia o que os alunos liam e o que eles gostariam de ler. Já a poetisa foi capaz de perceber a educação estética para além do moralizante, vendo na poesia um instrumento de humanização que possibilita ao leitor a inserção em um mundo que instiga a reflexão e a sensibilidade (...)."

Em A palavra enquanto brinquedo: representação da infância na obra de Arnaldo Antunes, de André Pinheiro, traz uma interpretação de poemas de várias obras de Arnaldo Antunes, apontando a riqueza de sentidos que surgem da brincadeira com a palavra. Embora não faça menção direta ao ensino, o ensaio é uma contribuição para o professor interessado em conhecer a poética de Antunes, bem como levar esta rica poesia para o espaço escolar. Pinheiro sintetiza de modo preciso o viés escolhido para sua reflexão: "A verdade é que Arnaldo Antunes se relaciona com a palavra de forma semelhante como a criança se relaciona com um brinquedo. A matéria concreta e a visualidade de seus versos dão a impressão de que o leitor está diante de um objeto quase tridimensional. Depois, as constantes mudanças de suporte de um mesmo texto provam que a poesia é para ele algo que se monta e desmonta ao seu gosto e interesse."

Numa perspectiva interdisciplinar, Jaquelânia Aristides Pereira em seu artigo Poesia e música na sala de aula: experiência com o poema "A flor na festa", de Cecília Meireles, reflete sobre um experimento de musicalização de poemas realizado com alunos de escolas públicas. O ensaio alia uma análise detida do poema "A flor na festa" à vivência de leitura que conduziu o infante à criação de uma melodia para o poema. Segundo Jaquelânia Aristides, "os fatores de musicalidade do poema são captados de forma intuitiva pelo leitor infanto-juvenil", conforme aconteceu com uma criança de 8 anos que cria uma melodia alegre para o poema, ao estilo de uma cantiga de roda. Ressaltamos a importância de acreditar na capacidade das crianças de reinventarem os poemas, de oferecerem modos de execução musical que nem sequer imaginávamos. Por certo, este procedimento aproxima o leitor do texto favorecendo uma formação sensível, lúdica e criativa.

Os dois artigos que seguem são resultados de intervenções realizadas para pesquisa de Mestrado no POSLE-UFCG. Destaco nas duas experiências a escolha de textos que favorecem um diálogo profícuo com a cultura popular, algo ainda bastante incipiente nas práticas de leitura literária.

O artigo Palmas, gritos, assovios: a leitura de cordel na sala de aula, de Hadoock E. A. de Medeiros e José Hélder Pinheiro Alves relatam e refletem sobre a leitura, com alunos do ensino médio, do folheto Os animais têm razão ou As sete constituintes, do poeta Antonio Francisco. O destaque está no modo como os leitores vão realizando uma performance da leitura caracterizada pela expressividade da fala das personagens animais. A leitura oral, ao modo como foi realizada, além de assumir um caráter lúdico, também contribui para a reflexão sobre questões sociais postas 
no folheto. Os autores destacam que "A chave para o envolvimento dos alunos com os folhetos lidos esteve principalmente no processo metodológico escolhido", que privilegiou o debate, a leitura compartilhada e a livre expressão dos leitores.

Já Ananília M. E. da Silva e Márcia Tavares, em Uma botija na sala de aula: leitura de romance na educação de jovens e adultos, trazem o recorte de uma experiência de leitura com o romance $A$ botija, da escritora paraibana, radicada em Natal, Clotilde Tavares. A retomada no romance do folheto $O$ Romance do Pavão misterioso, de José Camelo de M. Rezende, estimula as pesquisadoras a levarem o folheto para sala de aula. Este procedimento contribui para que o leitor vivencie, na prática, a leitura literária como espaço de diálogo com outras obras literárias. O ponto de partida não é o ensinamento de uma teoria - por exemplo, a intertextualidade - mas vivenciar relações complexas e estimulantes de leitura. A recepção dos leitores, segundo o artigo, foi de envolvimento, de mergulho na fantasia que a narrativa possibilita. Parece que todos tomaram acento no voo do Pavão misterioso da leitura.

Como se pode observar, os cinco artigos que fazem parte do Dossiê trazem a vivência com a poesia como eixo da reflexão. Poesia ofertada nas antologias com autores e temas diversificados, visando uma experiência sensível com o poema; vivência com a palavra poética como brinquedo e, portanto, algo lúdico, que estimula a reflexão e a percepção das ambiguidades das palavras; vivência da poesia enquanto espaço de projeção de novos ritmos e harmonias, num diálogo profícuo com a música; vivência com a poesia popular no contexto da sala de aula, estimulada pela riqueza da oralidade dos folhetos, da fantasia que propiciam e da reflexão crítica sobre a realidade que favorecem.

Por fim, o que se espera é que estas reflexões possam contribuir com o trabalho cotidiano do professor em sala de aula. Isto é, que o profissional se convença de que é possível vivenciar a literatura de um modo participativo, em que os leitores em formação possam ser sujeitos de suas leituras. E mais: que a leitura literária se efetive como prática e não como ensino de um saber sobre literatura. Mas para efetivar uma proposta nesta perspectiva é necessário se desvestir do modelo historicista de ensino, já bastante enraizado. É preciso reinventar o modo de ensinar, afinal, como nos alertou Cecília Meireles há bastante tempo - "A vida só é possível reinventada."

José Hélder Pinheiro Alves (POSLE-UFCG)

Maria Marta dos Santos Silva Nóbrega (POSLE-UFCG) 